University of Louisville

ThinkIR: The University of Louisville's Institutional Repository

Electronic Theses and Dissertations

$5-2021$

\title{
A spatial analysis of supply-demand of public transportation in Jefferson County, Kentucky.
}

Nastaran Abdoli

University of Louisville

Follow this and additional works at: https://ir.library.louisville.edu/etd

Part of the Environmental Design Commons, Environmental Policy Commons, Geographic Information Sciences Commons, Human Geography Commons, Infrastructure Commons, Other Geography Commons, Physical and Environmental Geography Commons, Policy Design, Analysis, and Evaluation Commons, Social and Cultural Anthropology Commons, Spatial Science Commons, Transportation Commons, Transportation Engineering Commons, Urban, Community and Regional Planning Commons, and the Urban Studies Commons

\section{Recommended Citation}

Abdoli, Nastaran, "A spatial analysis of supply-demand of public transportation in Jefferson County, Kentucky." (2021). Electronic Theses and Dissertations. Paper 3641.

https://doi.org/10.18297/etd/3641

This Master's Thesis is brought to you for free and open access by ThinkIR: The University of Louisville's Institutional Repository. It has been accepted for inclusion in Electronic Theses and Dissertations by an authorized administrator of ThinkIR: The University of Louisville's Institutional Repository. This title appears here courtesy of the author, who has retained all other copyrights. For more information, please contact thinkir@louisville.edu. 


\title{
A SPATIAL ANALYSIS OF SUPPLY-DEMAND OF PUBLIC TRANSPORTATION IN JEFFERSON COUNTY, KENTUCKY
}

\author{
By \\ Nastaran Abdoli \\ B.S, Urmia University, 2010 \\ M.A, University of Tennessee, 2018
}

\begin{abstract}
A Thesis
Submitted to the Faculty of the College of Arts and Sciences of the University of Louisville in Partial Fulfillment of the Requirements for the Degree of
\end{abstract}

\author{
Master of Science \\ in Applied Geography \\ Department of Geography and Geosciences \\ University of Louisville \\ Louisville, Kentucky \\ Louisville, KY
}

May 2021 

A SPATIAL ANALYSIS OF SUPPLY-DEMAND OF PUBLIC TRANSPORTATION IN JEFFERSON COUNTY, KENTUCKY

By

Nastaran Abdoli

A Thesis Approved on

April 26, 2021

By the following Thesis Committee

Wei Song

Charlie H Zhang

Sumei Zhang 


\section{ACKNOWLEDGEMENT}

I would like to express my gratitude to my advisor and my committee chair, Dr. Wei Song, for his guidance, patience, and insight during this endeavor, supporting and encouraging my work from the beginning. I would also like to thank my committee

members, Dr. Charlie H. Zhang and Dr. Sumei Zhang for helpful comments. I would also love to express my appreciation to the Department of Geography and Geosciences, Center for Geographic Information Sciences and Donald J. Biddle for providing the software package and GIS troubleshooting.

I am also thankful for the help of Stuart MacLean, transportation planner at TARC, and Aida Copic, the executive director of TARC. They kindly provided me with the data and answered all my questions. 


\title{
ABSTRACT
}

\section{A SPATIAL ANALYSIS OF SUPPLY-DEMAND OF PUBLIC TRANSPORTATION IN JEFFERSON COUNTY, KENTUCKY}

\author{
Nastaran Abdoli
}

26 April 2021

Public transportation is important as it serves individuals, especially the transitdependent population, by providing a basic mobility service to these people and all others who rely on public transportation. This research utilized estimating public transportation demand and supply to analyze the spatial patterns of public transportation in Jefferson County, Kentucky. The study focuses on the transit-dependent population, and it considers indicators of age, poverty status, vehicle ownership, and foreign-born population with less than five years residency in the United States. This study conducted a public transit supply-demand analysis to identify areas with imbalanced supply and demand in Jefferson County at the Traffic Analysis Zone. 


\section{TABLE OF CONTENTS}

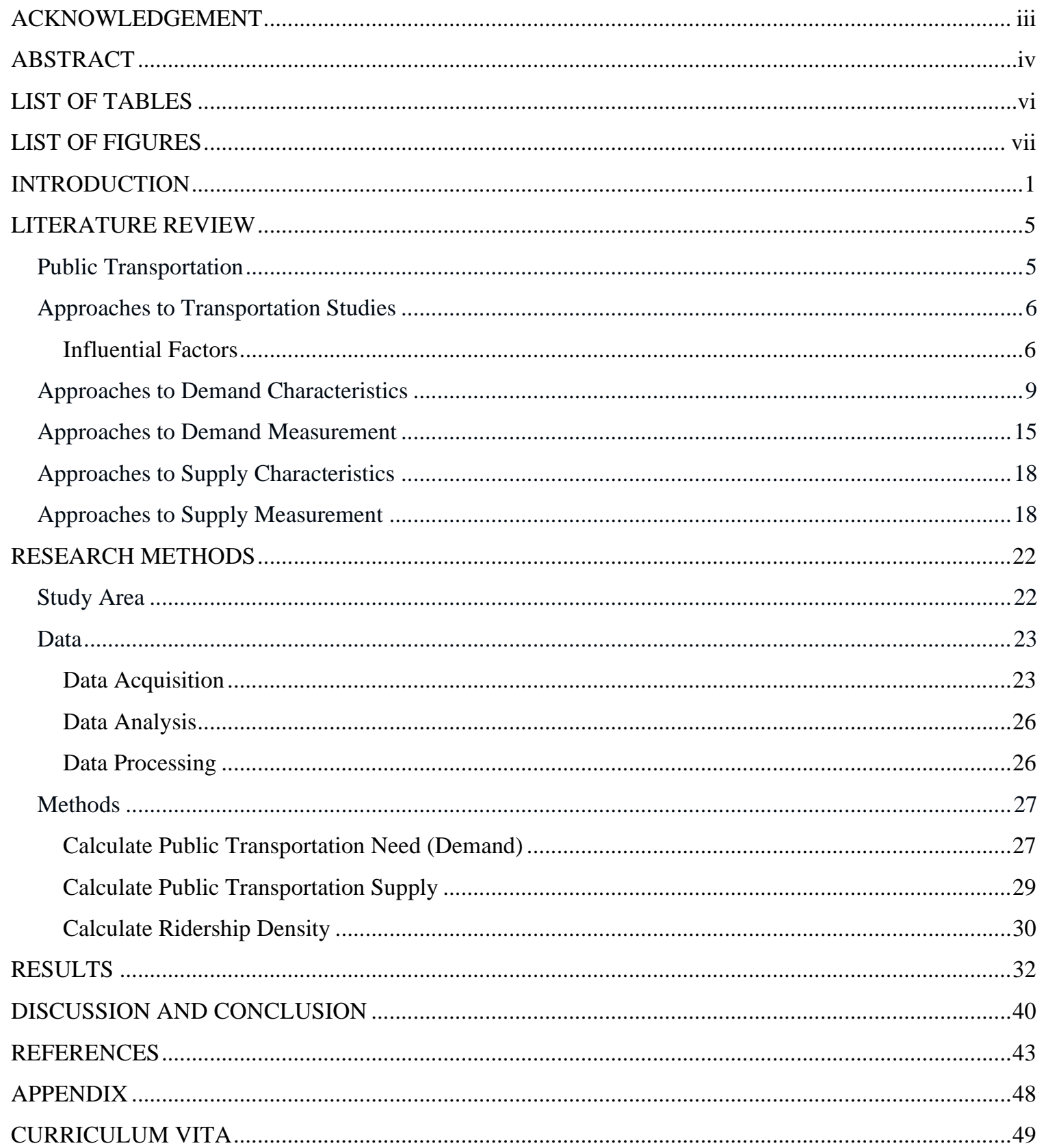




\section{LIST OF TABLES}

Table 1. Percentage of Population Distribution of Bus Ridership at Traffic Analysis Zone

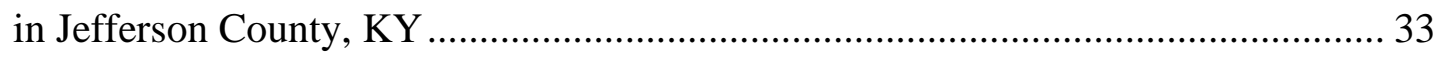

Table 2. Percentage of Population Distribution based on Need-Score Estimate at Traffic

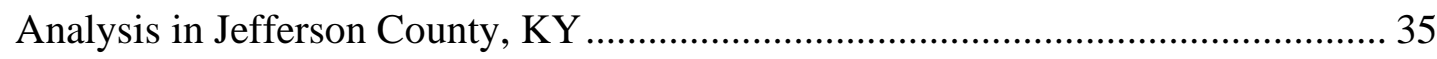

Table 3. Percentage of Population Distribution based Supply-Index Estimate at Traffic

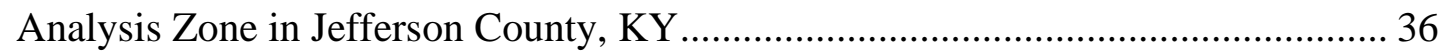

Table 4. Percentage of Population Distribution in Transit Gap Areas at Traffic Analysis

Zone in Jefferson County, KY ......................................................................... 38 


\section{LIST OF FIGURES}

Figure 1. Frequency of Transit-Dependency Indicators in the Reviewed Literature ....... 10

Figure 2. Bus Routes and Bus Stops in Jefferson County at Traffic Analysis Level ....... 23

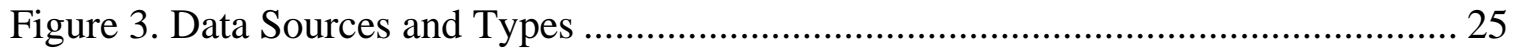

Figure 4. Bus Ridership Density in Jefferson County, KY at Traffic Analysis Zones Level

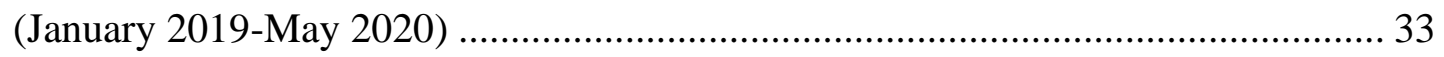

Figure 5. Population Distribution based on Need-Score (NS) Estimate at Traffic Analysis

Zone in Jefferson County, KY ............................................................................ 34

Figure 6. Public Transportation Supply Index Estimate in Jefferson County, KY at Traffic

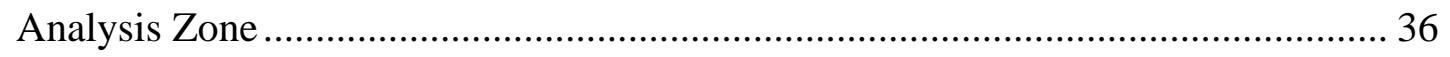

Figure 7. Public Transportation Need-Supply Gap Areas in Jefferson County, KY at

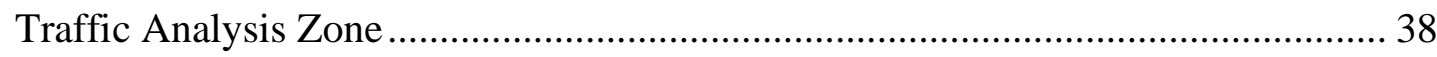




\section{INTRODUCTION}

Public transportation is of great importance in serving individuals, especially to transit-dependent populations and all others without access to a car. It provide basic mobility service and access to employment, community resources, medical care, and recreational opportunities in communities across America (Kwan and Hashim 2020). Benefits of public transportation have been studied over the years and include but are not limited to health benefits and decreased the number of traffic injuries (Kwan and Hashim 2016), reduced energy-related CO2 emissions (Kwan and Hashim 2020), increasing

physical activity (Rissel et al. 2012), and community inclusion (Gershon 2005). The word transit-dependent population refers to those who are too young, too old, too poor or who are physically disabled or unable to drive (Kenyon, Lyons, and Rafferty 2002; Stanley and Vella-Brodrick 2009; Grengs 2015), unwilling to drive, or those who do not have access to private vehicles (Grengs 2015; Lachapelle et al. 2016; Lubitow, Rainer, and Bassett 2017; Franklin and Chavis 2019; Aman and Smith-Colin 2020; Jiao and Cai 2020; Sharma et al. 2020).

Across America, many people rely on public transportation as their only means of transportation. According to the American Public Transportation Association, 9.9 billion trips are being made using public transportation in 2019, 34 million weekday trips million, and approximately 6800 organizations provide public transportation in the 
United States (APTA 2021). Like many cities in America, Jefferson County in Kentucky is primarily based on automobiles. Nevertheless, there is an opportunity to improve the public transit ridership and gradually reinforce a more public transit-oriented system. The statistics show that $76 \%$ of the U.S. population drive alone, while the same is about $82 \%$ for Kentucky. Besides, $2 \%$ of the U.S. population ride the bus, while in Kentucky, 3\% ride the bus (Louisville Metro Government 2016). It can be said that there is room for improving a transit system that gradually can reinforce a shift toward a more public transit-oriented system. In addition, it is estimated that $21 \%$ of Americans ages over 65 do not drive and usually are dependent on alternate means of transportation for more than ten years after cessation of driving (Bailey 2004).

The importance of public transportation can be understood through an extensive survey conducted by the American Transportation Planning Association covering over 700,000 passengers and is the most comprehensive demographic report of public transit riders. The survey showed that public transit riders have an enormous impact on America's economy, with $87 \%$ of public transit trips directly impacting the economy by connecting people to employers needing workers and retail and entertainment venues. It is noteworthy that $71 \%$ of public transportation riders across the country are employed, and another 7\% are students (Hughes-Cromwick n.d.).

Public transportation has a significant role in the economy and in providing people with mobility. Therefore, understanding the spatial pattern of public transportation and the potential demand is essential to evaluate if the service supply meet the demands of the population. Studies that have addressed such matters and identified the transit gap between demand and supply paid special attention to vulnerable populations or transit- 
disadvantage groups. Junfeng Jiao (2013) coined the term "transit deserts," which refers to the gap areas between public transportation supply and demand. In other words, transit deserts are the overlapping areas of high volume of public transit demand and low supply. Such investigations help better understanding the public transit service provisions and high-demand areas.

This research investigated the spatial distribution of bus ridership in Jefferson County and estimated the public transit demand and supply using a Need-Score (NS) and SupplyIndex (SI). The study area included a set of 559 Traffic Analysis Zones (TAZ) to establish an understanding of the spatial distribution of public transit ridership and socioeconomic and demographic factors associated with bus ridership. In Jefferson County, the Transit Authority of River City (TARC) manages public transit. The annual bus boarding was recorded 12.5 million with over 42000 average weekday trips in the serving areas (Aida Copic 2019). TARC network includes 43 routes, serving five Jefferson, Bullitt, Oldham in Kentucky, and Clark and Floyd in Indiana. TARC service area in Jefferson County, KY, was chosen as the focus of this research (TARC Home TARC n.d.) because the high frequency and high usage routes are mainly located in Jefferson County.

The objective of this study was threefold. First, a Need Score (NS) was calculated to quantify the relative demand for transit in each TAZ. Second, a Supply Index (SI) was developed to measure the level of service provided by TARC in each TAZ. The spatial distribution of actual ridership was also analyzed and then compared to the modelestimated demand pattern. The final objective of this study was to perform a public transit 
supply-demand gap analysis by investigating the spatial mismatch between transit supply and demand across Jefferson County at the TAZ level. In addition, the main social, economic, and demographic characteristics of the transit gap areas were explored.

This thesis contributes to urban transportation research by offering a case study of a large public transit system. It also tested the effectiveness of a quantitative, GIS-based approach in evaluating the relative demand and supply levels. Considering both demand and supply can help future planning and service provisions to prioritize the in-need population. It also evaluated the ridership pattern, which allowed comparing the existing ridership and the estimated demand and also to examine the effectiveness of such estimates in Jefferson County, KY. 


\section{LITERATURE REVIEW}

The literature review starts with the discussion of the background and various approaches toward public transportation studies which include studying the factors that can affect or be affected by public transportation, the spatial coverage of the public transit system, transit system design, and the role of policymaking and governments on public transportation. Then, it focuses on the first approach and explores the factors that affect

public transportation following by a discussion of population demographics and common methods for estimating demand and supply.

\section{Public Transportation}

Public transportation is widely considered as an environmentally sustainable mode compare to private vehicles, which the excessive use generates environmental and social problems in cities such as pollution, noise, and traffic congestion (Garrido, De Oña, and De Oña 2014). Typical public transportation systems are bus, trolleybus, metro, regional rail, and other modes that operate on prescribed lines/routes and schedules. In this research, the term public transportation refers to bus. Benefits of public transportation have been studied over the years include decreased number of traffic injuries and health benefits, reduced energy-related CO2 emissions (Kwan and Hashim 2020), increasing physical activity (Vuchic 2002; Rissel et al. 2012), and community 
inclusion (Gershon 2005). In addition, public transportation provides mobility and access to employment, community resources, medical care, and recreational opportunities in communities across America (Kwan and Hashim 2020).

Notably, the distribution of public transportation may not be equal throughout a region. It can impede access to jobs and limit opportunities for residents who have a poor connection with public transit. Studying the level of demand and supply balance can help to identify the influential factors that affect ridership and it encompasses sociodemographic characteristics, equity and justice issues, land use patterns, and service quality (Currie 2004; Wells and Thill 2012; Foth, Manaugh, and El-Geneidy 2013; Grengs 2015; Manaugh, Badami, and El-Geneidy 2015; Ricciardi, Xia, and Currie 2015; Litman 2019). The following sections discuss the common approaches in public transportation research.

\section{Approaches to Transportation Studies}

\section{Influential Factors}

In public transportation studies, understanding the underlying factors that can affect or be affected by public transportation can provide a holistic view of the public transit operation. These factors range from socioeconomic to demographic characteristics and environmental indicators (Heath and Gifford 2002; Bamberg, Hunecke, and Blöbaum 2007; Chiou, Jou, and Yang 2015; Fu and Juan 2017). 
For example, Jago Dodson, Nich Buchanan, Brendan Gleeson, and Neil Sipe (2007) investigated the social dimensions of socio-spatial transport disadvantage within the city of Gold Coast in Australia using the GIS technique. They considered the indicators of low socioeconomic indexes for areas (SEIFA) households, unemployed population; lowincome households; persons aged less than 14 years, persons aged greater than 65 years; renter households paying less than $\$ 150$ per week; mortgage holders paying less than $\$ 600$ per week. Their findings suggested connectivity between areas of high unemployment and employment concentration. In addition to the failure of the public transport system in providing good intra-urban connectivity to major employment, concentrations are some policy concerns (Dodson et al. 2007). Similarly, Robert Cervero, Jin Murakami, and Mark Miller (2010) explored a direct ridership model (DRM) for predicting bus rapid transit (BRT) patronage in Southern California using variables of private dwellings with no internet connection, rent, and English proficiency, employment in low-skill industries, education unemployment, and familial status. Their findings suggested the importance of service intensity, high levels of intermodal connections and employment density can increase the BRT ridership (Currie 2004; Cervero, Murakami, and Miller 2010; Currie et al. 2010). These types of studies applied methods of regression models and GIS-based analysis.

Another aspect of studies in public transportation explored the spatial coverage of the public transit system and considered the travel time, the time it takes to reach stops, fares, cost, and distance (Zhang et al. 2018). Similarly, GIS has been the primary modeling environment of such studies. In addition, the matter of service coverage also focuses on people's accessibility (Martínez and Viegas 2009; Zhou et al. 2012; Djurhuus 
et al. 2014; Cheng and Chen 2015; Djurhuus et al. 2016; Guzman and Oviedo 2018a; Bezyak et al. 2020). In some studies, the accessibility of special groups of people has been addressed (Blumenberg and Shiki 2003). For instance, Elizabeth Cahill Delmelle and Irene Casas (2012) explored the spatial accessibility and equitable distribution concerning neighborhood socioeconomic characteristics in Cali, Colombia, regarding access to the system itself and access to three distinct activities the city. Their findings suggested that walking access to the BRT system was the greatest for middle-income groups and most limited for neighborhoods in the highest and lowest socioeconomic strata. They concluded that accessibility values to activities were largely bound to the spatial distribution pattern of activities, and it was the most equitable for intentionally dispersed recreation sites and it was the least for spatially clustered hospitals (Delmelle and Casas 2012; Habibian and Hosseinzadeh 2018; Hatamzadeh and Hoseinzadeh 2020; Hosseinzadeh and Baghbani 2020).

Similarly, Jago Dodson, Nich Buchanan, Brendan Gleeson, and Neil Sipe (2006) investigated the social dimensions of studies that focus on transport disadvantaged groups. According to them, the transit disadvantaged population includes groups of lowincome people, beneficiaries and unemployed, children and youth, women, elderly, disabled, outer urban dwellers, and ethnic minorities. They suggested that research needs to account for spatial analytical methodologies and social differentiation in the need level in urban areas (Dodson et al. 2006).

Throughout the literature, the transit system design that focuses mainly on network analysis is another common approach in transportation studies (Banihashemi and Haghani 2000; Bagherinezhad et al. 2020). 
The last approach is investigating the role of governments and policy implementations on public transportation (Marsden and Reardon 2017; Hossack 2020; Huang et al. 2020) as well as the matter of social equity and social justice in public transport service provision (Staes, Hill, and Ward 1999; Ward 2005, 2009; Guzman and Oviedo 2018a). For instance, Luis A. Guzman and Daniel Oviedo (2018) have investigated the pro-poor subsidy by the government of Bogotá, Colombia, from an accessibility perspective. The authors found a progressive trend in the current structure of the pro-poor subsidies and alternative scenarios coverage increase, which would improve accessibility and equity for those with access to the subsidy (Guzman and Oviedo 2018b).

As can be seen, public transportation studies address a wide variety of issues, and based on the objective of this study, researchers have taken certain paths. Therefore, the rest of the sections will explain the first approach mentioned earlier, which is the focus of this research and covers a range of topics, including population demographics and the methods for estimating the volume of public transit demand and supply.

\section{Approaches to Demand Characteristics}

Public transportation has a significant role in serving individuals, and demand can be measured by considering transit dependency. The main question is who the transitdependent population is? The American Public Transportation Association (APTA) defines a transit-dependent population as people in the transit-dependent market with no personal means of transportation or who do not have access to such an option or might be unable to drive or unwilling to drive. This category includes people of low income, children, the elderly, people with disabilities, and those that other types of transportation 
do not meet their travel needs (Lovely and Brand 1982). In other words, transitdependent populations or transit-disadvantage populations rely on public transportation for their daily needs. According to the reviewed literature, they are the ones who are too young, too old, or too poor or who are physically disabled or unable to drive (Kenyon, Lyons, and Rafferty 2002; Stanley and Vella-Brodrick 2009; Grengs 2015) or unwilling to drive or those who do not have access to private vehicles (Grengs 2015; Lachapelle et al. 2016; Lubitow, Rainer, and Bassett 2017; Franklin and Chavis 2019; Aman and Smith-Colin 2020; Sharma et al. 2020). For instance, Beverly Ward (2005) found that low-income people and racial/ethnic minorities are concentrated at the city's urban center, away from jobs, goods, and services, and public transport is often their only reliable transportation option. His findings also suggested that the level of service varies from location to location (Ward 2005). Figure 1. shows the most frequent indicators in examining transit dependency that has been used in the reviewed literature.

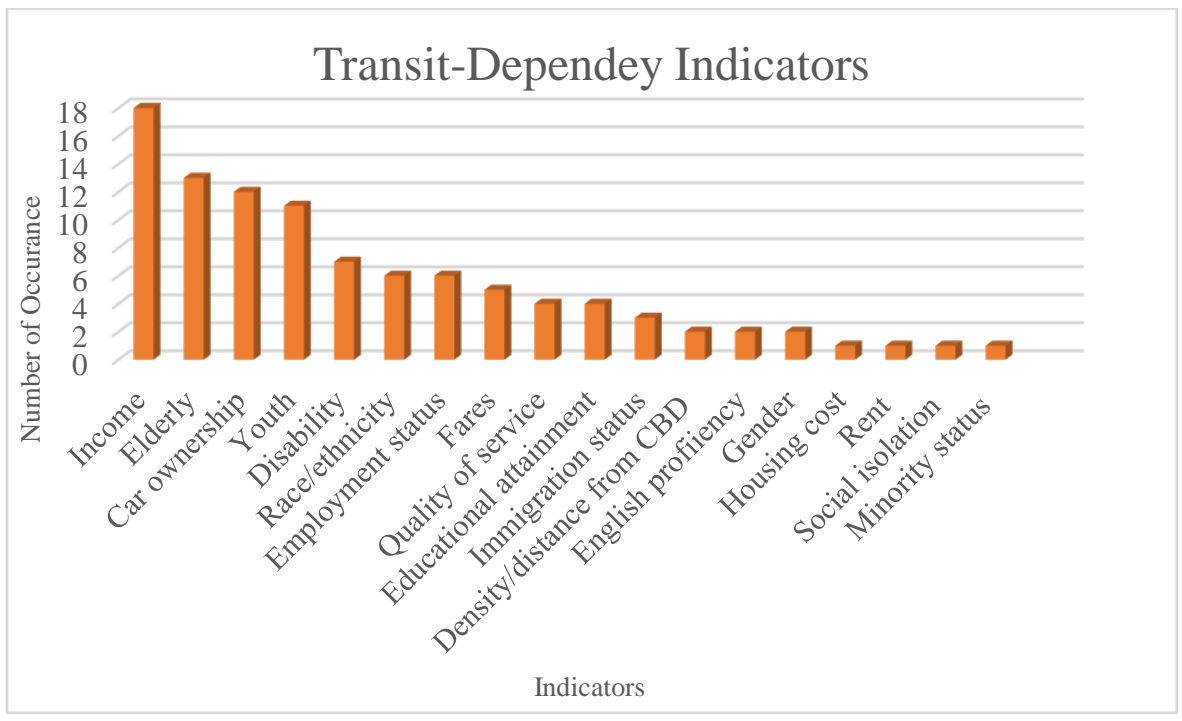

Figure 1. Frequency of Transit-Dependency Indicators in the Reviewed Literature 
The most common variables for assessing transit-dependency in the cited literature include income (Ircha and Gallagher 1985; Starrs and Perrins 1989; Currie 2004; Martinelli and Medellin 2007; Sanchez and Brenman 2007; Tribby 2009; Currie et al. 2010; Mamun and Lownes 2011; Foth, Manaugh, and El-Geneidy 2013; Farber et al. 2014; Popoks et al. 2014; Grengs 2015; Manaugh, Badami, and El-Geneidy 2015; Ricciardi, Xia, and Currie 2015; Carleton and Porter 2018; Adli, Chowdhury, and Shiftan 2019; Aman and Smith-Colin 2020), race/ethnicity (Starrs and Perrins 1989; Martinelli and Medellin 2007; Sanchez and Brenman 2007; Wells and Thill 2012; Foth, Manaugh, and El-Geneidy 2013; Grengs 2015), gender (Starrs and Perrins 1989; Martinelli and Medellin 2007), car ownership (Currie 2004; Currie et al. 2010; Mamun and Lownes 2011; Jiao 2017; Litman 2019; Aman and Smith-Colin 2020), employment status (Currie 2004; Currie et al. 2010; Foth, Manaugh, and El-Geneidy 2013; Popoks et al. 2014; Ricciardi, Xia, and Currie 2015; Aman and Smith-Colin 2020), immigration status (Manaugh and El-Geneidy 2011; Foth, Manaugh, and El-Geneidy 2013; Aman and Smith-Colin 2020), English proficiency (Sanchez and Brenman 2007; Carleton and Porter 2018), disability (Ircha and Gallagher 1985; Starrs and Perrins 1989; Currie 2004; Sanchez and Brenman 2007; Currie et al. 2010; Mamun and Lownes 2011; Aman and Smith-Colin 2020), elderly (Ircha and Gallagher 1985; Starrs and Perrins 1989; Currie 2004; Martinelli and Medellin 2007; Sanchez and Brenman 2007; Tribby 2009; Currie et al. 2010; Mamun and Lownes 2011; Farber et al. 2014; Popoks et al. 2014; Ricciardi, Xia, and Currie 2015; Carleton and Porter 2018; Chen et al. 2019), youth (Ircha and Gallagher 1985; Starrs and Perrins 1989; Currie 2004; Martinelli and Medellin 2007; Tribby 2009; Currie et al. 2010; Mamun and Lownes 2011; Farber et al. 2014; Popoks et 
al. 2014; Carleton and Porter 2018; Aman and Smith-Colin 2020), educational attainment (Currie et al. 2010; Manaugh and El-Geneidy 2011; Farber et al. 2014; Aman and SmithColin 2020), density/distance from CBD (Central Business District) (Currie 2004; Currie et al. 2010), minority status (Carleton and Porter 2018). Considering these indicators helped to link the spatial distribution of services and population.

For example, considering population demographic indicators, Graham Currie (2004) has applied the indicators of adults without cars, accessibility, persons aged over 60 years, persons on a disability pension, adults on a low-income, adults not in the labor force, and students to evaluate the distribution of demand of public transit. His findings suggested that bus network could not provide service to all areas distribution of needs was patchy, suggesting a scattered distribution of high and low scores with no particular trend toward inner versus outer areas being either high or low scores, very low need scores in undeveloped areas and no areas with the worst-case combination of need service (Currie 2004). In a later study in 2010, he applied the indicators of adults without cars, accessibility, persons aged over 60 years, persons on a disability pension, adults on a low income, adults not in the labor force, students, persons five to nine years (Currie 2004; Currie et al. 2010).

Similarly, Xiaoba Yao (2007) calculated the potential demand using land-use characteristics including population density, the employment rate (percentage of people who have jobs), job density (total jobs in the TAZ divided by the area of the TAZ), the average number of jobholders per household, percentage of home workers. The socioeconomic characteristics included income: percentages of jobholders in each of the three income statuses (below the poverty line, between 100-150\% of the poverty line 
income, above $150 \%$ of the poverty line income). Car ownership included percentages of jobholders whose households have 0,1 , or $2+$ vehicles, respectively, and network structure which included density of public transit stops in the TAZ (Yao 2007).

In a study, Alexa Delbosc and Graham Currie (2010) investigated the social exclusion of disadvantaged transport groups and its effect on well-being. They found out that people who face both transport disadvantage and social exclusion are more likely to be unemployed, alone parents, receiving a disability pension, and not owning a car (Delbosc and Currie 2011a). In another study on the same topic, they found out that correlations between transport disadvantage and social exclusion are small and inconsistent; however, the effects of the associated indicators with transport disadvantage indicators on public transportation ridership remained significant (Delbosc and Currie 2011).

Fang Zhao and Thomas Gustavson (2013) mapped out the demographic groups that demand public transit in Miami-Dade County. They identified and located four demographic groups with high transit service demand using four criteria: housing affordability, employment, household income, and transit coverage. They found out traveling by bus is not a considerable option for low-income and poor communities and those who do not have a car because it is slow, less direct, and expensive (Zhao and Gustafson 2013).

Nicole Foth, Kevin Manaugh, and Ahmen M. El-Geneidy (2013) explored transit dependency factors by measuring the relationship between social disadvantage and accessibility to jobs transit travel time in the Toronto region over time. They utilized social indicators of the percentage of unemployment, immigrants with less than five years 
of residency, and rent (households that spent more than $30 \%$ of income on rent). The differences between socially disadvantaged groups and the rest of the population job accessibility based on low-skill jobs and all other jobs were measured for 1996 and 2006. The authors concluded that accessibility to jobs was the same. However, a steady improvement in accessibility to jobs and a longer transit travel time was observed in 2006 compared to 1996 . The results showed that the most socially disadvantaged group developed a significant increase in accessibility and decreased transit travel time over the years (Foth, Manaugh, and El-Geneidy 2013).

In a study conducted in Perth, Australia Anthony Michael Ricciardi, Jianhong Xia, and Graham Currie (2015) explored the equity issue in the distribution of public transit for three separate disadvantaged populations, including elderly, low-income households, and no-car household to utilizing GIS to identify the spatial distribution pattern. The relative public transit supply concerning the demand of the separate target groups was evaluated using Gini coefficients and Lorenz curve. They found out that Perth's public transportation system is centrally focused, and it is unevenly distributed, and the elderly had the highest inequity of distribution. They concluded that the groups who more commonly use public transportation are also more disadvantaged by its distribution (Ricciardi, Xia, and Currie 2015).

Joe Grengs (2015) conducted his research in the Detroit metropolitan region by deriving and evaluating non-work accessibility indicators among specific social groups, using the factors of race, ethnicity, income, and poverty status. According to him, vulnerable social groups of African Americans, Hispanics, low-income households, and households in poverty experience advantage in physical accessibility over more 
privileged groups for multiple trip purposes, including convenience stores, childcare facilities, religious organizations, and hospitals, and distinct disadvantage inaccessibility to shopping and supermarkets (Grengs 2015).

\section{Approaches to Demand Measurement}

Approaches to demand measurement include estimating the transit dependency level as a measure of demand. In some methods, socio-demographic factors have been considered for demand measurement, and in some others, vehicle ownership has been the main focus. This chapter will explain the most common methods of estimating the volume of public transportation demand.

Calculating the demand can be conducted considering the socio-demographic and environmental factors. For example, transportation demand can be estimated by assembling transport need indicators for a series of areas and defining a single Need Score (NS) for each area based on the relative indicator values. This method was used in studies conducted by Currie (2004) and Currie et al. (2010). The indicators included adults without a car, accessibility, persons aged over 60 years old, persons on a disability pension, adults on low-income, adults not in the labor force, and students. The values for each indicator were standardized using the original value, minimum value, and maximum value. Each standardized indicator was given a weight calculated based on travel behavior in low travel areas, and the calculations generated a composite NS (Currie 2004; Currie et al. 2010). 
Kaitlyn Toms and Wei Song (2016) have applied the same method that Currie et al. (2010) have used in their studies and applied the method to the case of Jefferson County, KY, by examining the public transportation supply-demand gap analysis. The authors considered the factors of percent of persons age five to nine, persons aged above 65 years old, unemployment, poverty status, car ownership, and the Central Business District (CBD) distance. They found out that many gap zones were in the interior of the study area close to the CBD, and the lowest service levels were located on the outside borders, and high Need Scores to be concentrated in the core area (Toms and Song 2016).

Similarly, Yao (2007) investigated the potential demand for public transit for commuting trips by introducing a Need Index (NI) calculated by employing a multiple regression which accounts for land use and socioeconomic variables or any other contributing variables that are not related to the transit systems. The index measured the relative magnitude of potential demand in Atlanta, Georgia, at the TAZ level utilizing GIS for spatial analysis (Yao 2007).

As mentioned earlier, in some other methods, vehicle ownership has been the focus of measuring demand. The U.S. Department of Transportation suggested a formula to calculate the transit-dependent population at the block group level for each city. This method focuses on car ownership and considers the population of drivers and non-drivers and carpooling ratio. The indicators to calculate the transit dependency level include population over 16 years old, the population age 12-15 years old, the population living in group quarters ${ }^{1}$, and the non-institutional population living in group quarters. This

\footnotetext{
${ }^{1}$ All people not living in housing. There are two types of group quarters, institutional, such as correctional facilities (prison, jail), nursing homes, or mental hospitals and non-institutional, such as college dormitories, military barracks, group homes, missions, or shelters (U.S. Census Bureau, 2020)
} 
method does not consider the transit dependency level related to population characteristics and calculate the population of drivers and non-drivers, and also accounts for non-institutional population and people living in group quarters, a factor that has not been widely considered in previous research (Jiao and Dillivan 2013; Jiao 2017).

Javad J. C. Aman and Janille Smith-Colin (2020) calculated the demand by assembling the standardized z-score values at the census tract (CT) in Dallas, Texas, for ten different indicators of income, vehicle ownership, unemployment, immigration status, education, youth, seniors, socially isolated, disabled, and transit user population. Moreover, the CTs were grouped in quartiles, and each quartile contained $25 \%$ of the total CTs in the study area. In this way, the high and low demand areas were identified (Aman and Smith-Colin 2020).

The same strategy was used in earlier studies by Foth et al. (2013), and variables were standardized for comparison purposes and summed to create a composite indicator value (Foth, Manaugh, and El-Geneidy 2013).

The current thesis will use the same methods used by Currie (2004) and Currie et al. (2010) to estimate the volume of public transit demand because it incorporates transit dependency factors and population demographics in the study area. The current research considered the percent of youth (age 10-14), percent of elderly (over 60 years), percent of the foreign-born population with less than five years residency in the U.S., percent of no vehicle households, and percent of people below poverty line. 


\section{Approaches to Supply Characteristics}

The literature that has investigated the supply aspect of public transportation includes a wide variety of service characteristics. The indicators that have been used in these studies varies by the goals and objective of the study. The characteristics will be explained along with the different measurement methods.

\section{Approaches to Supply Measurement}

Calculating the supply includes considering indicators related to the transit service. Currie (2004) used modeling based on the analysis of bus routes, stops, and timetables. He defined the location of facilities, shops, and so forth for 14 trip purposes. Then the transport model measured the quality of travel by public transport (routes, access and egress times, frequencies, travel times, and fares) for five time periods. The analysis generated a matrix of generalized travel cost results for 14 trip purposes by fivetime and 387 travel zones (some 27,000 trip cost outputs). For each period, the transport model measured walk access time to bus stops, wait time, fare, and travel time on buses, and walk egress time. Distances above $400 \mathrm{~m}$. were identified as the threshold for feasible walk access to and from buses (Currie 2004; Hosseinzadeh 2021; Hosseinzadeh et al. 2021b, 2021a; Kang, Ataeian, and Amiripour 2021).

Similarly, Currie et al. (2010) created a measure of public transit supply for each Collective Center District (CCD) in Perth, Australia, which represented the share of the $\mathrm{CCD}$ in terms of transit service. For each stop, a measure of service frequency was 
calculated, which was the 'total number of service arrivals per week,' and access distance to each stop/station was then measured for each CCD with typical thresholds of walk access (termed walk 'buffers') for public transport modes: access to bus stop $=400$, access to tram stop $=400 \mathrm{~m}$, access to rail station $=800 \mathrm{~m}$. Then, a combined measure of service frequency (vehicle trips per week) and access distance was then computed for each CCD using GIS software. The measure represented a combined measure of service level (SL) and access distance for each CCD which represented the CCD's supply index (Currie et al. 2010).

Jiao et al. (2013) have used the indicators of the number of bus and rail stops, frequency of service for each bus and rail stops per day (weekday service), number of routes, length of bike routes, and sidewalks (miles) in each block group (Jiao 2013). In later studies, he expanded the supply indicators and added the total length of low-speed limit roads (miles) and intersection density (Jiao 2017). The z-scores of each indicator were aggregated to represent the level of transit supply for each block group. Finally, the Z-score of public transit demand and supply was subtracted, and a final numerical value was calculated for each block group to determine an excess or lack of supply (Jiao and Dillivan 2013; Jiao 2017).

Aman et al. (2020) have used four major indicators to assess what they called "good transit" to evaluate the public transit supply. These indicators included connectivity to the network, connectivity to a destination, service frequency, flexibility, and time efficiency. Connectivity to network included bus stop service coverage area, which considered the total area of the CT, the number of bus stops in each CT; density of bus stop measure route coverage by calculating the relative measure of the route length in 
each CT to the length of the street network, ADA accessibility was measured using ADA ramps. Indicators for connectivity to destinations included: number of accessible lowsalary jobs in one hour, the number of accessible medical facilities in one hour, and bus arrivals at different times. The indicators used to calculate flexibility and time efficiency included: number of routes, the number of low-salary jobs accessible in $30 \mathrm{~min}$, the number of medical facilities accessible in $30 \mathrm{~min}$, and the number of grocery stores accessible in 30 min (Aman and Smith-Colin 2020).

For evaluating the supply-demand analysis, Mingming Cai, Junfeng Jiao, and Minghai Luo, and Yanfang Liu (2020) identified transit deserts for low-income areas in Wuhan metropolitan area in China. The results showed relatively high percentages of transit-dependent commuters are in suburban areas, while the communities with low percentages of transit-dependent commuters were concentrated in the central areas (Cai et al. 2020).

The current research has utilized the SI method by Currie (2004) to calculate the volume of public transit supply level in Jefferson County, KY because it considers the total number of bus arrivals at each stop and considering a $400 \mathrm{~m}$ ( 0.25 mile $)$ threshold for accessibility measures and the coverage area of those buffers to the total area of the TAZ.

\section{Need-Supply Gap Analysis and Transit Deserts}

The analysis of demand and supply helps to identify areas with high demand and low service, which are known as transit gaps or transit deserts. One of the early studies 
investigating the transit gap was the study conducted by Currie (2004). He explored the spatial distribution of public transit supply-demand gap analysis to assess geographic distribution and quality of public transportation and identify the gaps between community needs and the public transport service provisions (Currie 2004).

The term "transit desert" has been recently introduced to public transportation studies equivalent to transit gaps. Transit desert refers to the areas that there is a gap between public transit demand and supply. According to Jiao (2013), transit deserts are known as the gap areas between high transit-dependent populations and low levels of transit supply. They found out that transit deserts were typically concentrated close to the downtown where cities most often have their major transit centers. Supply highest concentrations were observed in or near the CBD, and service supply decreased as the distance increased (Jiao and Dillivan 2013; Jiao 2017). Likewise, Aman et al. (2020), in their work on identifying transit deserts as areas of overlapping high transit dependency and low transit supply. They found out that extreme transit deserts were in areas that reflected low supply across all transit supply factors, mainly located in southern parts of Dallas, TX (Aman and Smith-Colin 2020).

The following chapter will explain the methods that have been borrowed from previous works and have been applied to the current research. 


\section{RESEARCH METHODS}

This chapter explains the methods that have been used in this research and discusses the process of data collection, data analysis, and the study area. The focus will be on the computation of demand and supply indices based on the methods used in previous studies to estimate the levels of both demand for and supply of TARC services across TAZs in Jefferson County, KY.

\section{Study Area}

Louisville, Kentucky's largest city, sits on the Ohio River along the Indiana border with a population of 759640 based on CTPP demographic data, and total bus ridership for 17 months was recorded at 675756. In Jefferson County, TARC manages public transit. The Transit Authority of the River City (TARC) manages public transit service in Jefferson County, and it used to run 43 routes, serving five counties and two states of Kentucky and Indiana. It served Jefferson, Bullitt, Oldham counties in Kentucky, and Clark and Floyd counties in Indiana. Figure. 2 shows the bus routes and bus stops in Jefferson County. 


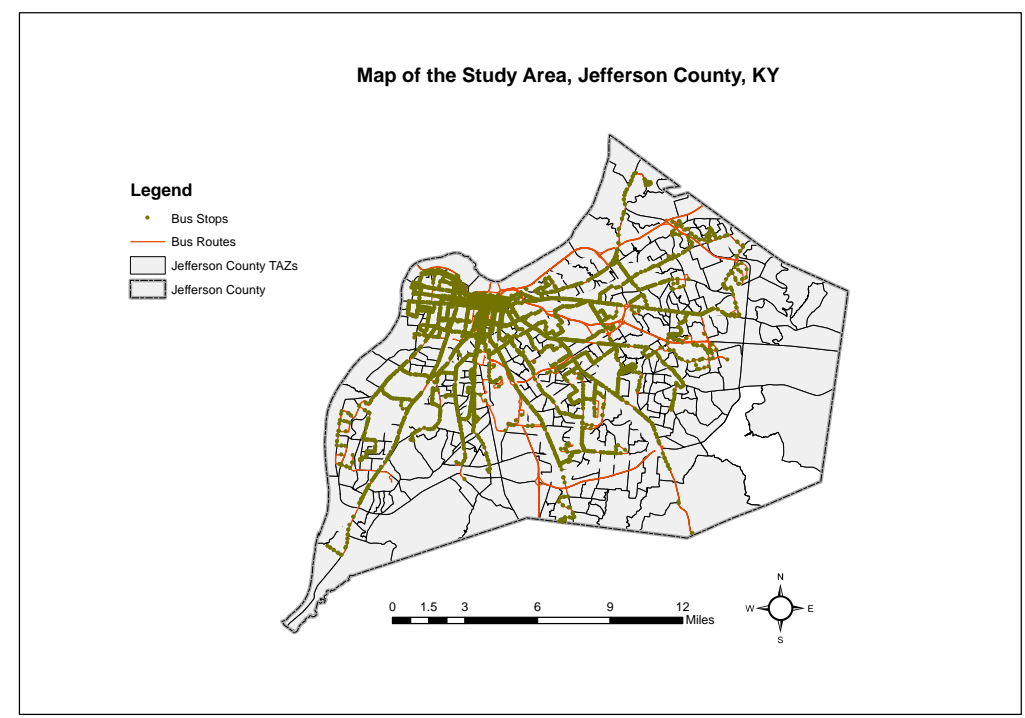

Figure 2. Bus Routes and Bus Stops in Jefferson County at Traffic Analysis Level

\section{Data}

\section{Data Acquisition}

The main sources of analysis for this study were obtained from the American Association of State Highway and Transportation Officials (AASHTO) and local and governmental agency of Louisville/Jefferson County Information Consortium (LOJIC) and Transportation Authority of River City (TARC).

The current research has conducted spatial analysis metrics, evaluated the volume of public transit demand and supply and the spatial distribution pattern of the existing bus ridership.

Demand was measured using the following data from the Census Transportation Planning Products (CTPP) demographic data: percent of youth (age 10-14 years old), 
percent of elderly (population over 60 years old), percent of the foreign-born population with less than five years residency in the U.S., percent of the population below poverty line and percent of population with no vehicle. The CTPP is the collection of census data products used by the transportation planning community, and it provides data that have enhanced value for transportation planning, analysis, and strategic direction (ctpp.org). The CTPP demographic data for 2012-2016 was chosen because it consisted of transportation-specific tabulations of the 5-year American Communities Survey (ACS). The level of analysis for this study is TAZ because they are partitioned according to variables most pertinent to travel choices (Yao 2007). Transit supply was measured using TAZ shapefile and Jefferson County shapefile was needed to display the population distribution. The shapefiles for those were obtained from CTPP products and LOJIC. The geospatial data and the shapefiles of bus stops and bus routes required to measure the public transport supply were acquired from LOJIC. The bus ridership, frequency, and scheduling data were obtained from TARC. Ridership data included the total number of monthly ridership at each stop for January 2019-May 2020. This data represented the total count of the monthly ridership at each bus stop. Figure 3. shows the data and sources that were used in this study. 


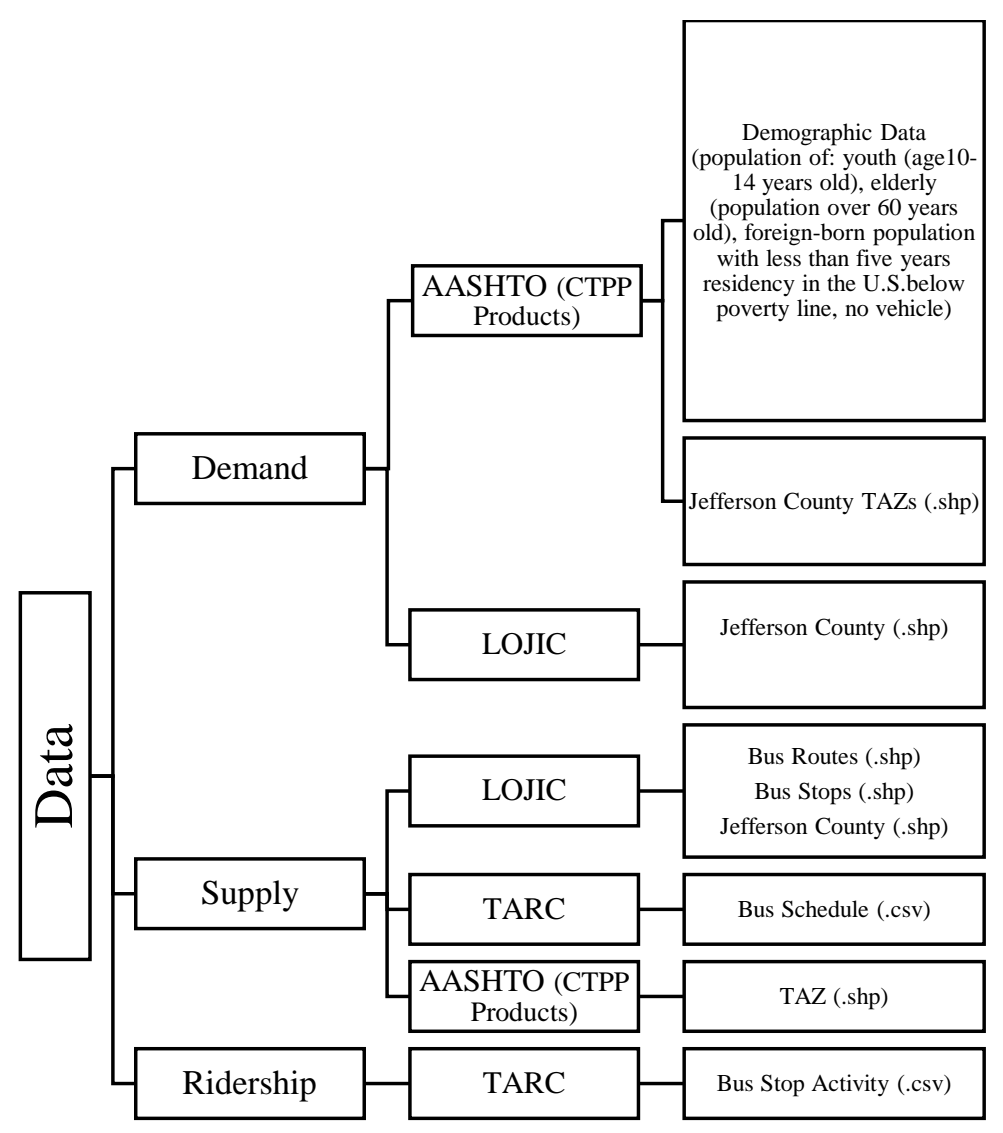

Figure 3. Data Sources and Types

- American Association of State Highway and Transportation Officials (AASHTO):

CTPP demographic data, Jefferson County TAZ shapefiles

- Louisville/Jefferson County Information Consortium (LOJIC): shapefiles of

Jefferson County, bus routes, and bus stops

- Transportation Authority of River City (TARC): bus stop activity (ridership, frequency, and scheduling) in the format of Excel tables format 


\section{Data Analysis}

This section explains the process of locating the ridership pattern in Jefferson County, KY. The method involved the estimate of a Need Score (NS), the estimate of a Supply Index (SI), and supply-demand gap analysis, and the analysis of the pattern of existing bus ridership.

This study utilized ArcGIS mapping and analytical platforms to perform geospatial analysis and create maps of the ridership pattern in Jefferson County, KY. The ArcGIS 10.7 software package was provided by the Center for Geographic Information Systems at the University of Louisville, Department of Geography and Geosciences. The calculations were conducted in ArcGIS and are based on the formulas discussed in the following sections. The tables obtained, including demographic data, were rearranged, and prepared to be used in ArcGIS.

\section{Data Processing}

The data processing for datasets in the previous section included matching the data retrieved from TARC, the total monthly ridership for each bus stop in Jefferson County for January 2019-May 2020. Data preparation for CTPP demographic data was conducted in Excel, where the total population in each TAZ, the percent of the population age 10-14, percent of the population over 60 years old, percent of the foreign-born population with less than five years residency in the U.S., percent of the population below poverty line and percent of the population with no vehicles were calculated for each TAZ for 559 TAZs in Jefferson County; however the analysis moved forward with 
522 TAZs with available ridership data and demographic tables were exported in ArcMap. The Jefferson County shapefile and TAZ shapefile were projected using the KY State Plane North (US Survey Feet) projection system that LOJIC applies to all the shapefiles. The projection of the shapefiles is necessary as it sets the coordinate system proper to the study area. The demographic tables were joined to Jefferson TAZ shapefiles using the spatial join function in ArcGIS. The spatial join function joins attributes from one feature to another based on the spatial relationship (ArcGIS desktop). This step prepared the data for public transit demand calculation.

The data processing for public transit supply included joining the shapefiles of bus routes and bus stops to the TAZ shapefile using the spatial join function. The produced shapefile was then joined to the bus schedule table prepared in Excel and then imported to ArcMap.

The bus stop activity data were merged for January 2019-May 2020, and the total ridership for each TAZ was calculated, added to the ArcMap, and joined to the TAZ shapefile that was produced earlier (included bus stops and bus routes). These steps prepared the data to be used in ArcGIS for analysis purposes.

\section{Methods}

\section{Calculate Public Transportation Need (Demand)}

This research employed the methods used by Currie (2010), in which several factors were used to create a one composite Need Score (NS) across the study area. In 
this study, a set of weights was assigned to the factors suggested by Currie et al. (2010). The indicators in the current research included percent of youth (age 10-14), percent of elderly (age over 60), percent of no vehicle households, percent of the foreign-born population with less than five years residency in the U.S., and percent below poverty line population for 559 TAZs. W1-W5 are the weights for the indicators which are the same weights that Currie $(2004,2010)$ used in his studies. The weights are assumed to be appropriate for this study because they reflect travel behavior and how certain characteristics might affect the ridership. The following equation was used (1):

$$
\mathrm{NS}_{\mathrm{TAZi}}=\left(\mathrm{SI}_{\mathrm{TAZi}} * \mathrm{~W} 1\right)+\left(\mathrm{SI} 2_{\mathrm{TAZi}} * \mathrm{~W} 2\right)+\cdots+\left(\mathrm{SI}_{\mathrm{TAZi}} * \mathrm{~W} 5\right)
$$

where $\mathrm{NS}_{\mathrm{TAZ}}$ is the public transit Need Score for $i$ th TAZ of the total 559 TAZs. SI1 $1_{\text {TAZi }}$ through SI5 $5_{\text {TAZi }}$ are standardized values of variables. SI1 is percent youth age 1014, SI2 is the percent of elderly (age over 60), SI3 is the percent of foreign-born population with less than five years residency in the U.S., SI4 is the percent of the population below poverty status, and SI5 is the percent of households with no vehicle. WI1-WI5 are the weight for the indicators $\mathrm{W} 1=0.24, \mathrm{~W} 2=0.16, \mathrm{~W} 3=0.14, \mathrm{~W} 4=0.24$, $\mathrm{W} 5=0.22$. Once public transit need scores are computed for each TAZ, they are standardized using equation (2):

$$
X_{i}^{S T D}=\frac{\mathrm{X}_{\mathrm{i}}-\mathrm{X}_{\mathrm{Min}}}{\mathrm{X}_{\mathrm{Max}}-\mathrm{X}_{\mathrm{Min}}}
$$


where $\mathrm{X}_{\mathrm{i}}^{\mathrm{STD}}$ is the standardized index for $\mathrm{TAZ} \mathrm{Z}_{\mathrm{i}}, \mathrm{X}_{\mathrm{i}}$ is the original need score for $\mathrm{TAZ}_{\mathrm{i}}, \mathrm{X}_{\mathrm{Min}}$ is the minimum value, and $\mathrm{X}_{\mathrm{Max}}$ is the maximum value of the need scores. Need score values were standardized so that both the supply index and need score can be compared.

Need Score across all TAZs was categorized into groups based on relative deviations from the mean value. The values were ranked low, below average average, above average, and high.

\section{Calculate Public Transportation Supply}

For creating a supply index for each TAZ, this study utilized the method used by Currie (2004). The service level (SL) or frequency of each TARC bus stop was measured by the total number of arrivals per week at each bus stop. Access distance to each bus stop was then measured assuming a threshold of $400 \mathrm{~m}$ (0.25 miles) walking distance. Essentially, the service level index for each TAZ is calculated by placing a $400 \mathrm{~m}(0.25$ mile) buffer around each stop and comparing those areas to the total area in the TAZ. Most studies define the catchment area as within $400 \mathrm{~m}$. from a bus stop because it is the approximate range of distances pedestrians will walk to transit stops (Eisenberg-Guyot et al., 2019). This value is then multiplied by the service level measure per each stop. This approach accounts for the spatial coverage of a TAZ, which is covered by walk catchments to public transport and also their relative service levels. A supply index (SI) 
that combines service frequency and access distance was then computed for each TAZ using equation 3 (Currie et al. 2010).

$$
S I_{T A Z}=\sum_{N}\left(\frac{\operatorname{Area}_{B n}}{\text { Area }_{T A Z}}\right) * S L_{B n}
$$

where $\mathrm{SI}_{\mathrm{TAZ}}$ is the supply index for a TAZ under the investigation, $\mathrm{N}$ is the total number of walk access buffers to stops/stations in each TAZ, and Bn is the buffer $\mathrm{n}$ for each stop/station in each TAZ, Area is the square kilometer spatial area of the TAZ, SL is the service level measure (total number of bus arrivals per week). Using the same approach as for NS, once SI is computed for each TAZ, they were standardized using equation (2) and categorized into groups based on relative deviations from the mean value. The values were ranked low, below average average, above average, and high. These categories from both the NS and the SI were used to set up a contingency table, particularly to illustrate and map overlapping areas of low service and high demand. These areas can be identified as transit gaps or transit deserts in Jefferson County.

\section{Calculate Ridership Density}

The ridership density was calculated by considering the total ridership in each TAZ and the area of TAZ. The following equation (4) was used for calculating ridership density: 


$$
D R_{T A Z i}=\frac{N R_{T A Z i}}{A_{T A Z i}}
$$

where $\mathrm{DR}_{\mathrm{TAZi}}$ is the ridership density in the $\mathrm{TAZ}_{\mathrm{i}}, \mathrm{NR}_{\mathrm{TAZi}}$ is the total population ridership in $\mathrm{TAZ}_{\mathrm{i}}$, and $\mathrm{A}_{\mathrm{TAZi}}$ is the total area of the $\mathrm{TAZ}_{\mathrm{i}}$ in square kilometers, which were calculated using the calculating geometry function in ArcGIS.

The following chapter will explain the result of the analysis and the population distribution in the study area. 


\section{RESULTS}

This chapter explains the volume of demand and supply of public transportation in Jefferson County, KY. First, the existing ridership pattern in Jefferson County was examined using the bus stop activity report, which included the total monthly ridership at each bus stop as it was recorded on automated passenger counting machines in the TARC bus system in 522 TAZs. Besides, the total population was calculated 759640 based on CTPP demographic data for all 559 TAZs, and the total bus ridership was recorded at 675756 for January 2019-May 2020 for all 522 TAZs (approximately $80 \%$ of the bus stops in Jefferson County with available ridership data). Figure 4. shows the total ridership density pattern in Jefferson County.

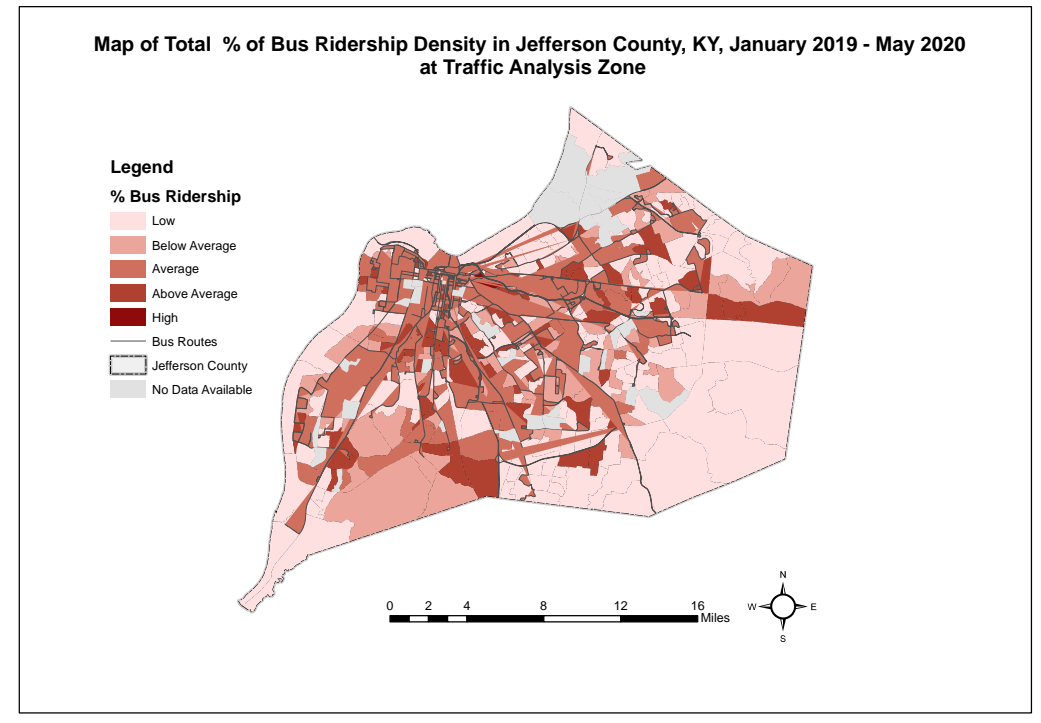


Figure 4. Bus Ridership Density in Jefferson County, KY at Traffic Analysis Zones Level (January 2019-May 2020)

The spatial distribution of the percent of ridership density in Jefferson County showed that areas with high and above-average ridership density are mainly scattered across Jefferson County, and a specific spatial pattern cannot be recognized, but more highdensity ridership patches can be seen in the inner-city. In addition, suburban and undeveloped areas showed low levels of ridership density compare to inner cities.

Table 1. Percentage of Population Distribution of Bus Ridership at Traffic Analysis Zone in Jefferson County, KY

\begin{tabular}{llllllll}
\hline $\begin{array}{l}\text { Ridership } \\
\text { Density }\end{array}$ & Ridership & Age 10-14 & Elderly & $\begin{array}{l}\text { Length of } \\
\text { Residency }\end{array}$ & $\begin{array}{l}\text { Below } \\
\text { Poverty Line }\end{array}$ & No Vehicle & Population \\
\hline High & 16.2 & 5.9 & 17.7 & 0.2 & 7.9 & 1.7 & 0.6 \\
\hline Above Average & 61.8 & 6.8 & 20.0 & 2.0 & 13.0 & 5.8 & 20.4 \\
\hline Average & 11.1 & 6.8 & 20.8 & 2.0 & 12.6 & 6.0 & 15.0 \\
\hline Below Average & 7.2 & 6.6 & 21.0 & 2.0 & 9.3 & 3.0 & 19.8 \\
\hline Low & 3.6 & 7.0 & 20.7 & 1.6 & 8.2 & 2.8 & 44.2 \\
\hline
\end{tabular}

As can be seen, almost $78 \%$ of the total ridership happened to be in high and above-average ridership density areas, out of which it includes $21 \%$ of the total population in the study area. The elderly accounted for $37.7 \%$, and people below the poverty line for $21.7 \%$ of the total population in those areas, which is higher in those areas than the population of the same groups in areas with low and very low ridership density. The percent of the population age $10-14$ is almost $12.7 \%$, no vehicle household accounted for $7.5 \%$, and foreign-born population with less than five years residency about $2.2 \%$ of the total population in those TAZs. The indicators of no vehicle 
households and length of residency found to be less important compare to other factors. In addition, it can be said that based on the ridership data and population analysis, the elderly and low-income population are the main users of public transportation in Jefferson County.

In addition, the demand was estimated by calculating a composite NS, which accounts for demographic characteristics. Figure 5. shows the population distribution of the potential demand in categories of low, below average, above average, and high. The higher the score, the higher the potential demand for public transit.

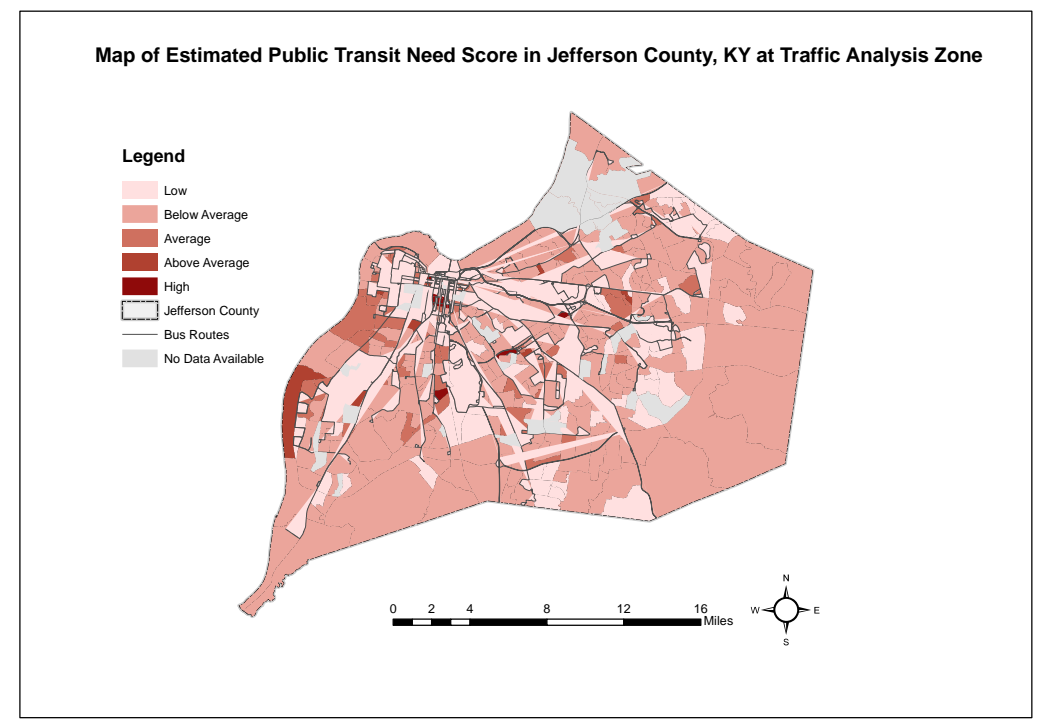

Figure 5. Population Distribution based on Need-Score (NS) Estimate at Traffic Analysis Zone in Jefferson County, KY

Spatial distribution of NS in high and above-average areas can be seen in the core and the west side of Jefferson County. Most suburban areas showed a low level of NS. 
Table 2. Percentage of Population Distribution based on Need-Score Estimate at Traffic Analysis in Jefferson County, KY

\begin{tabular}{llllllll}
\hline NS & Ridership & Age 10-14 & Elderly & Length of & Below Poverty & No & Population \\
& & & & Residency & Line & Vehicle & \\
\hline Zero/No & 23.0 & 0 & 0.5 & 0.1 & 0 & 0 & 0.28 \\
Data & & & & & & & \\
\hline Low & 12.0 & 6.7 & 0.8 & 0.8 & 4.5 & 0.04 & 12.8 \\
\hline Below & 45.8 & 6.9 & 1.3 & 1.4 & 8.3 & 0.1 & 69.0 \\
Average & & & & & & & \\
\hline Average & 14.6 & 7.1 & 1.7 & 4.1 & 19.2 & 0.7 & 15.1 \\
\hline Above & 1.0 & 6.8 & 3.9 & 6.9 & 23.2 & 1.4 & 1.3 \\
Average & & & & & & & \\
\hline High & 3.6 & 4.8 & 3.9 & 2.8 & 42.7 & 5.2 & 1.2 \\
\hline
\end{tabular}

Utilizing the need score (NS) calculation shows that $4.6 \%$ of the total bus ridership happens in high and above-average NS areas. The demographic characteristics in those TAZs include $65.9 \%$ below the poverty line, $11.6 \%$ youth age $10-14,9.7 \%$ foreign-born population with less than five years residency in the U.S., 7.8\% elderly, and $6.6 \%$ no vehicle households. It can be said that people below the poverty line have the highest need for public transportation in the study area.

The following section includes the results of the public transit supply analysis. As mentioned in the previous chapter, the volume of supply of public transportation was calculated using the Supply Index (SI) method. Figure 6. shows the result of SI analysis, and the scores were categorized based on the standard deviation from mean in the study area as high, above average, average, below average, and low. 


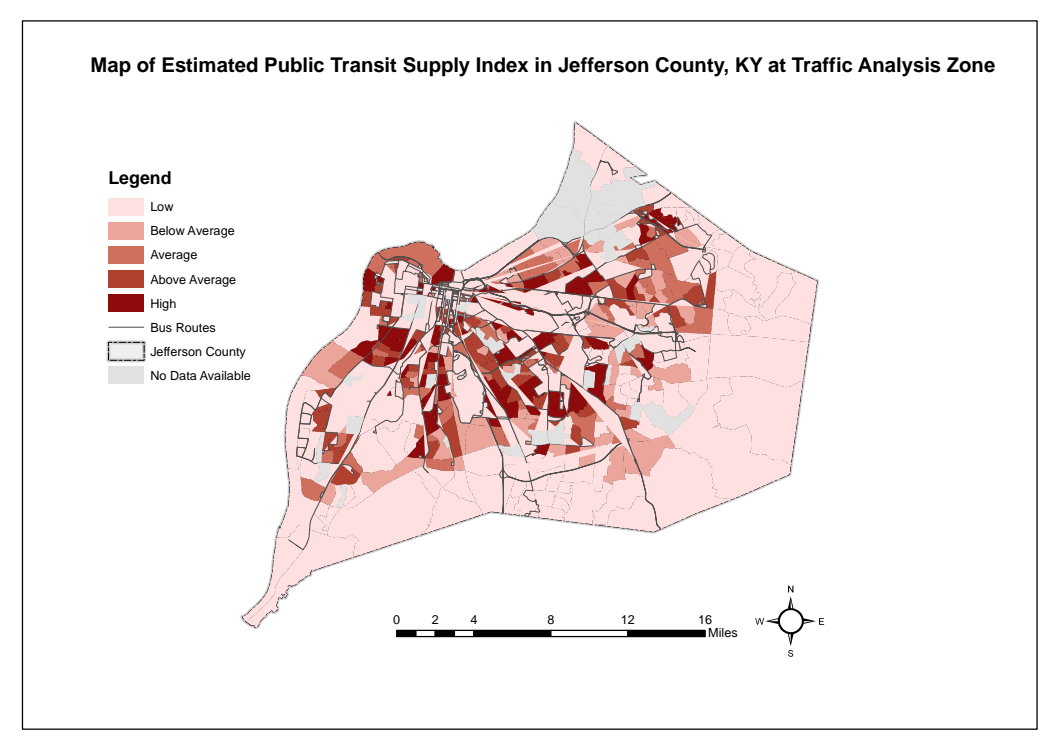

Figure 6. Public Transportation Supply Index Estimate in Jefferson County, KY at Traffic Analysis Zone

Table 3. Percentage of Population Distribution based Supply-Index Estimate at Traffic $\underline{\text { Analysis Zone in Jefferson County, KY }}$

\begin{tabular}{llllllll}
\hline SI & Ridership & Age 10-14 & Elderly & $\begin{array}{l}\text { Length of } \\
\text { Residency }\end{array}$ & $\begin{array}{l}\text { Below } \\
\text { Poverty Line }\end{array}$ & No Vehicle & Population \\
\hline Low & 11.9 & 7.2 & 1.4 & 1.2 & 7.2 & 0.2 & 34.0 \\
\hline $\begin{array}{l}\text { Below } \\
\text { Average }\end{array}$ & 17.6 & 6.2 & 1.4 & 2.5 & 8.9 & 0.3 & 16.3 \\
\hline $\begin{array}{l}\text { Average } \\
21.3\end{array}$ & 6.9 & 1.5 & 0.3 & 11.5 & 1.7 & 15.6 \\
\hline $\begin{array}{l}\text { Above } \\
\text { Average }\end{array}$ & 23.1 & 6.8 & 20.6 & 1.5 & 13.0 & 6.9 & 18.0 \\
\hline High & 25.9 & 6.8 & 19.0 & 2.9 & 12.3 & 5.2 & 19.7 \\
\hline
\end{tabular}

It can be seen that $29.5 \%$ of the bus ridership happens in the areas with belowaverage and low-service areas, while $70.3 \%$ of the ridership happens in areas with aboveaverage service and is research focused on areas with low and below average service. More than $50 \%$ of the total population in Jefferson County live in areas with low and 
below average service (34\% of them live in areas with low service or zero services). It shows that almost half of the Jefferson County population is likely to suffer from insufficient public transit service. The population distribution analysis showed that out of people living in below-average service areas, $16.1 \%$ below the poverty line, $13.4 \%$ of the population in those TAZs age 10-14, $2.8 \%$ elderly, $3.7 \%$ foreign-born with less than five years residency in the U.S., and $0.5 \%$ are with no vehicle. It can be seen that vehicle ownership is not a significant indicator in areas below average and low service. The low income and age group of 10-14 holds a higher population in these TAZs than other factors and they are more likely to suffer from low levels of service distribution. In areas with an above-average service index, $41.2 \%$ are elderly population which means that a good level of service is provided to the elderly who might rely on public transportation. In other words, it shows elderly might not be the main group who suffer from the public transit supply distribution. Therefore, in Jefferson County, population below the poverty line is more likely to be affected by the uneven distribution of public transit supply.

The analysis of the volume of demand and supply of public transportation helped identifying the gap areas or transit deserts in Jefferson County. Figure 7 shows the transit gap areas in Jefferson County based on calculating the volume of public transit demand and supply by identifying the areas with the above average and high demand but low and below average service. 


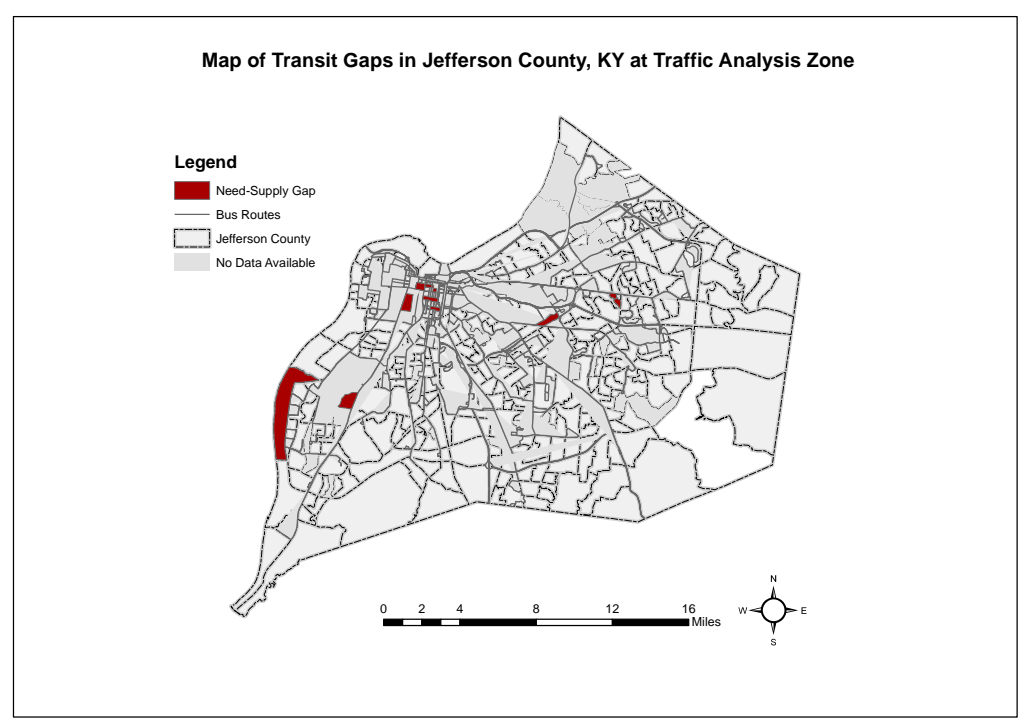

Figure 7. Public Transportation Need-Supply Gap Areas in Jefferson County, KY at Traffic Analysis Zone

The spatial distribution of transit gaps in Jefferson County shows that gap areas are in the core and on the west side of Jefferson County.

Table 4. Percentage of Population Distribution in Transit Gap Areas at Traffic Analysis Zone in Jefferson County, KY

\begin{tabular}{llllllll}
\hline Gap Areas & Ridership & $\begin{array}{l}\text { Age } \\
\mathbf{1 0 - 1 4}\end{array}$ & Elderly & $\begin{array}{l}\text { Length of } \\
\text { Residency }\end{array}$ & Below Poverty Line & $\begin{array}{l}\text { No } \\
\text { Vehicle }\end{array}$ & Population \\
\hline $\begin{array}{l}\text { High } \\
\text { Demand/Low } \\
\text { Service }\end{array}$ & 1.4 & 6.2 & 4.7 & 7.3 & 30.0 & 3.1 & 1.2 \\
\hline
\end{tabular}

As can be seen, the highest share of the population in transit desert areas belongs to low-income people with $30 \%$ of the total population in gap areas and $7.3 \%$ of the residents in the gap TAZs have been in the U.S. for less than five years. In addition, $6.2 \%$ are youth age 10-14 and elderly accounted for $4.7 \%$ of the population. The results 
showed that $1.2 \%$ of the total population of Jefferson County live in areas with low level of service and high levels of demand. 


\section{DISCUSSION AND CONCLUSION}

This research evaluated the volume of public transit supply and demand in Jefferson County, KY, at the TAZ level. High and above-average public transit demand areas were scattered across the study area, and undeveloped and suburban areas showed a low NS. Public transit supply in Jefferson County is centrally focused in inner city. The public transit SI had the lowest values in suburban areas and some TAZs in the core and on the west side of Jefferson County. Population below poverty line found out to the highest population living in areas with the highest NS. In addition, in low and below average transit supply areas, the majority of population are those below poverty line. The results of NS and SI estimates showed that the population below poverty line are likely to be more in need of public transit service, and they are also the ones who are likely to suffer more from the imbalanced distribution of supply.

This research identified the transit gap areas as scattered and patchy across the

study area. They were located both in the inner-city and on the west side of Jefferson County, and people below the poverty line were found to be the majority of the population living in transit gap areas.

The results of this study showed consistency with the findings of previous studies. For example, it identified gap areas both in the inner-city and the suburbs (Currie 2004). However, many of the gap areas in populated TAZs. Besides, this study shows that gaps 
are not located only in the suburbs and inner-city, rather it is more in the core and west side of Jefferson County, which is partially consistent with similar studies; however, it is not consistent with their findings that there is extreme spatial mismatch between demand and supply (Toms and Song, 2016).The findings of this research were consistent with the finding of a study conducted by Jiao (2020), he investigated the transit deserts in 52 cities, and he found that the transit deserts in Jefferson County are insignificant (Jiao 2019). In other words, he indicated there is not a significant spatial mismatch between supply and demand, which is consistent with the results of the current study.

This research also found out that gap areas are not mainly in the core city and downtown area, but they are located at the inner core and the west side of the town, which is not consistent with the literature (Toms and Song 2016Jiao and Divillian 2017). The results of this study are consistent with the findings of Aman et al. (2020), in which gap areas were overlapping areas of high demand in low supply. The results of this research were also consistent with Ricciardi et al. (2015), in part that the vulnerable population is more transit disadvantaged compared to other groups, but unlike their findings, the more disadvantaged group by the distribution of public transit supply in Jefferson County found to be the population below poverty line followed by foreign-born population with less than five years residency in the U.S. (Ricciardi, Xia, and Currie 2015). However, the bus ridership analysis showed elderly and population below poverty line were the main riders, and the elderly category did show significant transit disadvantage in Jefferson County.

The result of the current research showed that population distribution in transit desert areas includes $30 \%$ of people below the poverty line, which is much higher 
compared to other factors. The results showed that vehicle ownership is less important when it comes to the influential factors in public transit ridership. Although the concentration of supply in the inner and middle of the study area provides a high level of service to individuals, this research showed that considering both the demand and supply assessment and incorporating population characteristics can help identify the areas in extreme need of improved public transportation provisions. This research utilized a quantitative base and applied GIS techniques to incorporate the socio-demographic characteristics in bus ridership assessment and demand-supply analysis.

The limitations of this research include the lack of ridership data for all TAZs across Jefferson County because almost $80 \%$ of the buses have the automated passenger count, and the ridership data was not available for all TAZs. The weights that have been assigned to the indicators for calculating NS was borrowed from previous research, and more investigations can be conducted evaluating the suitability of those weight for Jefferson County. Future research can incorporate more variables to compute NS. Sensitivity analysis can also be conducted to help to identify the impact of different size buffers and assess the impact on SI. The findings of this study can be served as the basis for transportation planning purposes and for addressing the need of the transit-dependent population. 


\section{REFERENCES}

Adli, S. N., S. Chowdhury, and Y. Shiftan. 2019. Justice in public transport systems: A comparative study of Auckland, Brisbane, Perth and Vancouver. Cities 90:88-99.

Aida Copic. 2019. Equity in Action.

Aman, J. J. C., and J. Smith-Colin. 2020. Transit Deserts: Equity analysis of public transit accessibility. Journal of Transport Geography 89:102869.

Bailey, L. 2004. Aging Americans: stranded without options.

Bamberg, S., M. Hunecke, and A. Blöbaum. 2007. Social context, personal norms and the use of public transportation: Two field studies. Journal of environmental psychology 27 (3):190-203.

Cai, M., J. Jiao, M. Luo, and Y. Liu. 2020. Identifying transit deserts for low-income commuters in Wuhan Metropolitan Area, China. Transportation Research Part D: Transport and Environment 82:102292.

Carleton, P. R., and J. D. Porter. 2018. A comparative analysis of the challenges in measuring transit equity: definitions, interpretations, and limitations. Journal of Transport Geography 72:64-75.

Chen, Y., A. Bouferguene, Y. Shen, and M. Al-Hussein. 2019. Assessing accessibilitybased service effectiveness (ABSEV) and social equity for urban bus transit: A sustainability perspective. Sustainable Cities and Society 44:499-510.

Chiou, Y.-C., R.-C. Jou, and C.-H. Yang. 2015. Factors affecting public transportation usage rate: Geographically weighted regression. Transportation Research Part A: Policy and Practice 78:161-177.

Currie, G. 2004. Gap Analysis of Public Transport Needs:Measuring Spatial Distribution of Public Transport Needs and Identifying Gaps in the Quality of Public Transport Provision. Transportation Research Record: Journal of the Transportation Research Board 1895 (1):137-146.

Currie, G., T. Richardson, P. Smyth, D. Vella-Brodrick, J. Hine, K. Lucas, Janet Stanley, J. Morris, R. Kinnear, and John Stanley. 2010. Investigating links between transport disadvantage, social exclusion and well-being in Melbourne-Updated results. Research in transportation economics 29 (1):287-295.

Delbosc, A., and G. Currie. 2011. Using Lorenz curves to assess public transport equity. Journal of Transport Geography 19 (6):1252-1259. 
Delmelle, E. C., and I. Casas. 2012. Evaluating the spatial equity of bus rapid transitbased accessibility patterns in a developing country: The case of Cali, Colombia. Transport Policy 20:36-46.

Dodson, J., B. Gleeson, R. Evans, and N. Sipe. 2007. Investigating the social dimensions of transport disadvantage II: From concepts to methods through an empirical case study. Urban policy and research 25 (1):63-89.

Eisenberg-Guyot, J., A. V. Moudon, P. M. Hurvitz, S. J. Mooney, K. B. Whitlock, and B. E. Saelens. 2019. Beyond the bus stop: where transit users walk. Journal of transport \& health 14:100604.

Farber, S., K. Bartholomew, X. Li, A. Páez, and K. M. Nurul Habib. 2014. Assessing social equity in distance based transit fares using a model of travel behavior.

Transportation Research Part A: Policy and Practice 67:291-303.

Foth, N., K. Manaugh, and A. M. El-Geneidy. 2013. Towards equitable transit: examining transit accessibility and social need in Toronto, Canada, 1996-2006. Journal of Transport Geography 29:1-10.

Franklin, K., and C. Chavis. 2019. Transit Deserts: Baltimore City, Maryland.

Fu, X., and Z. Juan. 2017. Exploring the psychosocial factors associated with public transportation usage and examining the "gendered" difference. Transportation research part A: policy and practice 103:70-82.

Garrido, C., R. De Oña, and J. De Oña. 2014. Neural networks for analyzing service quality in public transportation. Expert Systems with Applications 41 (15):6830-6838.

Gershon, R. R. 2005. Public transportation: advantages and challenges. Journal of Urban Health 82 (1):7-9.

Grengs, J. 2015. Nonwork Accessibility as a Social Equity Indicator. International Journal of Sustainable Transportation 9 (1):1-14.

Guzman, L. A., and D. Oviedo. 2018a. Accessibility, affordability and equity: Assessing 'pro-poor' public transport subsidies in Bogotá. Transport Policy 68:37-51.

- 2018b. Accessibility, affordability and equity: Assessing 'pro-poor'public transport subsidies in Bogotá. Transport Policy 68:37-51.

Habibian, M., and A. Hosseinzadeh. 2018. Walkability index across trip purposes. Sustainable cities and society 42:216-225.

Hatamzadeh, Y., and A. Hoseinzadeh. 2020. Toward a deeper understanding of elderly walking for transport: An analysis across genders in a case study of Iran. Journal of Transport \& Health 19:100949. 
Heath, Y., and R. Gifford. 2002. Extending the theory of planned behavior: Predicting the use of public transportation 1. Journal of Applied Social Psychology 32 (10):2154-2189.

Hossack, M. A. 2020. Transportation Revenue and Expenditure Issues in Saskatchewan.

Hosseinzadeh, A. 2021. What affects how far individuals walk? SN Applied Sciences 3 (3):1-10.

Hosseinzadeh, A., M. Algomaiah, R. Kluger, and Z. Li. 2021a. E-scooters and sustainability: Investigating the relationship between the density of E-scooter trips and characteristics of sustainable urban development. Sustainable cities and society 66:102624.

- 2021b. Spatial analysis of shared e-scooter trips. Journal of Transport Geography 92:103016.

Hosseinzadeh, A., and A. Baghbani. 2020. WALKING TRIP GENERATION AND BUILT ENVIRONMENT: A COMPARATIVE STUDY ON TRIP PURPOSES. International Journal for Traffic and Transport Engineering 10 (3).

Huang, H.-J., T. Xia, Q. Tian, T.-L. Liu, C. Wang, and D. Li. 2020. Transportation issues in developing China's urban agglomerations. Transport Policy 85:A1-A22.

Hughes-Cromwick, M. Who Rides Public Transportation. American Public

Transportation Association. https://www.apta.com/research-technical-resources/researchreports/who-rides-public-transportation/ (last accessed 11 November 2020).

Ircha, M. C., and M. A. Gallagher. 1985. Urban transit: equity aspects. Journal of urban planning and development 111 (1):1-9.

Jiao, J. 2017. Identifying transit deserts in major Texas cities where the supplies missed the demands. Journal of Transport and Land Use 10 (1). https://www.jtlu.org/index.php/jtlu/article/view/899 (last accessed 24 February 2020).

- 2019. Understanding Transportation Related Infrastructure Access in 52 Major US Cities. University of Texas at Austin. Cooperative Mobility for Competitive Megaregions.

Jiao, J., and M. Dillivan. 2013. Transit Deserts: The Gap between Demand and Supply. Journal of Public Transportation 16 (3):23-39.

Kang, M. J., S. Ataeian, and S. M. Amiripour. 2021. A procedure for public transit OD matrix generation using smart card transaction data. Public Transport 13 (1):81-100.

Kenyon, S., G. Lyons, and J. Rafferty. 2002. Transport and social exclusion: investigating the possibility of promoting inclusion through virtual mobility. Journal of Transport Geography 10 (3):207-219. 
Kwan, S. C., and J. H. Hashim. 2020. Public transport and health. In Advances in Transportation and Health, 149-173. Elsevier.

Lachapelle, U., L. D. Frank, J. F. Sallis, B. E. Saelens, and T. L. Conway. 2016. Active transportation by transit-dependent and choice riders and potential displacement of leisure physical activity. Journal of planning education and research 36 (2):225-238.

Litman, T. 2019. Evaluating Transportation Equity. :66.

Lovely, M. E., and D. Brand. 1982. Atlanta transit pricing study: moderating impact of fare increases on poor.

Lubitow, A., J. Rainer, and S. Bassett. 2017. Exclusion and vulnerability on public transit: experiences of transit dependent riders in Portland, Oregon. Mobilities 12 (6):924-937.

Mamun, S. A., and N. E. Lownes. 2011. Measuring service gaps: accessibility-based transit need index. Transportation research record 2217 (1):153-161.

Manaugh, K., M. G. Badami, and A. M. El-Geneidy. 2015. Integrating social equity into urban transportation planning: A critical evaluation of equity objectives and measures in transportation plans in North America. Transport Policy 37:167-176.

Manaugh, K., and A. El-Geneidy. 2011. Who benefits from new transportation infrastructure? Using accessibility measures to evaluate social equity in transit provision. For Accessibility and planning: Challenges for Europe and North America. London, UK: Edward Elgar.

Marsden, G., and L. Reardon. 2017. Questions of governance: Rethinking the study of transportation policy. Transportation Research Part A: Policy and Practice 101:238251.

Martinelli, D., and L. Medellin. 2007. Assessment of Bus Transit Equity in Two Metropolitan Areas. Mid-Atlantic Universities Transportation Center, Region III.

Popoks, D., S. Kaplan, C. G. Prato, and A. A. Cedera. 2014. Using Connectivity for Measuring Equity in Transit Provision.

Ricciardi, A. M., J. Xia, and G. Currie. 2015. Exploring public transport equity between separate disadvantaged cohorts: a case study in Perth, Australia. Journal of Transport Geography 43:111-122.

Rissel, C., N. Curac, M. Greenaway, and A. Bauman. 2012. Physical activity associated with public transport use - a review and modelling of potential benefits. International journal of environmental research and public health 9 (7):2454-2478. 
Sanchez, T., and M. Brenman. 2007. Transportation equity and environmental justice; lessons from hurricane KatrinaIn: Paper Presented at The State of Environmental Justice in America 2007 Conference. Washington, March :29-31.

Sharma, I., S. Mishra, M. M. Golias, T. F. Welch, and C. R. Cherry. 2020. Equity of transit connectivity in Tennessee cities. Journal of Transport Geography 86:102750.

Staes, L., E. T. Hill, and B. Ward. 1999. Methods for Examining Environmental Equity Issues in Public Transportation.

Stanley, J., and D. Vella-Brodrick. 2009. The usefulness of social exclusion to inform social policy in transport. Transport Policy 16 (3):90-96.

Starrs, M., and C. Perrins. 1989. The markets for public transport: the poor and the transport disadvantaged. Transport Reviews 9 (1):59-74.

Toms, K., and W. Song. 2016. Spatial analysis of the relationship between levels of service provided by public transit and areas of high demand in Jefferson County, Kentucky. Papers in Applied Geography 2 (2):147-159.

Tribby, C. 2009. Assessing the effects of new public transportation routes: an equity analysis on the changing accessibility of Albuquerque, New Mexico.

Vuchic, V. R. 2002. Urban public transportation systems. University of Pennsylvania, Philadelphia, PA, USA 5:2532-2558.

Ward, B. G. 2005. Case studies in environmental justice and public transit Title VI reporting. National Center for Transit Research (US). 2009. Disaggregating Race and Ethnicity: Toward a Better Understanding of the Social Impacts of Transport Decisions. Public Works Management \& Policy 13 (4):354360.

Wells, K., and J.-C. Thill. 2012. Do Transit-Dependent Neighborhoods Receive Inferior Bus Access? A Neighborhood Analysis in Four U.S. Cities. Journal of Urban Affairs 34 (1):43-63.

Yao, X. 2007. Where are public transit needed-Examining potential demand for public transit for commuting trips. Computers, Environment and Urban Systems 31 (5):535550 .

Zhao, F., and T. Gustafson. 2013. Transportation needs of disadvantaged populations: where, when, and how? United States. Federal Transit Administration. 


\section{Acronyms}

\section{APPENDIX}

$\begin{array}{ll}\text { AASHTO } & \text { American Association of State Highway and Transportation Officials } \\ \text { ACS } & \text { American Communities Survey } \\ \text { APTA } & \text { American Public Transportation Association } \\ \text { BRT } & \text { Bus Rapid Transit } \\ \text { CBD } & \text { Central Business District } \\ \text { CCD } & \text { Census Collection District } \\ \text { CT } & \text { Census Tract } \\ \text { CTPP } & \text { Census Transportation Planning Products } \\ \text { CPTA } & \text { Comprehensive Public Transit Accessibility } \\ \text { DRM } & \text { Direct Ridership Model (DRM) } \\ \text { LOJIC } & \text { Louisville/Jefferson County Information Consortium } \\ \text { TARC } & \text { Transit Authority of River City } \\ \text { TAZ } & \end{array}$




\section{CURRICULUM VITA}

NAME:

ADDRESS:

DOB:

EDUCATION:
Nastaran Abdoli

2330 Crittenden Dr

Louisville, Kentucky, 40217

February 3, 1988

M.S., Applied Geography

University of Louisville

2019-2021 